\title{
Detection of deep low-frequency earthquakes in the Nankai subduction zone over 11 years using a matched filter technique
}

\author{
Aitaro Kato ${ }^{*}$ (1) and Shigeki Nakagawa
}

\begin{abstract}
To improve our understanding of the long-term behavior of low-frequency earthquakes (LFEs) along the tremor belt of the Nankai subduction zone, we applied a matched filter technique to continuous seismic data recorded by a dense and highly sensitive seismic network over an 11-year window, April 2004 to August 2015. We detected a total of $\sim 510,000$ LFEs, or $\sim 23 \times$ the number of LFEs in the JMA catalog for the same period. During long-term slow slip events (SSEs) in the Bungo Channel, a series of migrating LFE bursts intermittently occurred along the fault-strike direction, with slow hypocenter propagation. Elastic energy released by long-term SSEs appears to control the extent of LFE activity. We identify slowly migrating fronts of LFEs during major episodic tremor and slip (ETS) events, which extend over distances of up to $100 \mathrm{~km}$ and follow diffusion-like patterns of spatial evolution with a diffusion coefficient of $\sim 10^{4} \mathrm{~m}^{2} / \mathrm{s}$. This migration pattern closely matches the spatio-temporal evolution of tectonic tremors reported by previous studies. At shorter distances, up to $15 \mathrm{~km}$, we discovered rapid diffusion-like migration of LFEs with a coefficient of $\sim 10^{5} \mathrm{~m}^{2} / \mathrm{s}$. We also recognize that rapid migration of LFEs occurred intermittently in many streaks during major ETS episodes. These observations suggest that slow slip transients contain a multitude of smaller, temporally clustered fault slip events whose evolution is controlled by a diffusional process.
\end{abstract}

Keywords: Slow earthquake, Low-frequency earthquake, Matched filter technique, Rapid migration, Diffusion process

\section{Introduction}

In the past two decades, slow earthquakes have been detected in many active plate boundaries along the Pacific Rim (Peng and Gomberg 2010; Obara and Kato 2016). Slow earthquakes occur primarily in partially coupled areas, such as the shallower and deeper extensions of the strongly locked seismogenic zone along a plate boundary fault (Obara and Kato 2016; Araki et al. 2017; Bartlow 2020; Wallace2020; Yokota and Ishikawa 2020).

In the Nankai subduction zone, slow earthquakes are typically classified as either seismic or geodetic events, based on their characteristic time scales (Obara and Kato 2016). Deep tectonic tremor, one type of slow seismic

*Correspondence: akato@eri.u-tokyo.ac.jp

Earthquake Research Institute, University of Tokyo, 1-1-1 Yayoi, Bunkyo-ku, Tokyo 113-0032, Japan earthquake, is distributed quasi-continuously within a narrow belt-like zone along the downdip edge of the strongly locked seismogenic zone over a total length of $\sim 600 \mathrm{~km}$ (Obara 2002; Obara and Kato 2016). The waveforms of this deep tremor contain relatively energetic and impulsive signals that have been identified as low-frequency earthquakes (LFEs) by the Japan Meteorological Agency (JMA) (Katsumata and Kamaya 2003; Shelly et al. 2007a). Previous studies have proposed that tectonic tremor can be explained by a swarm of LFEs, each of which occurs as shear slip along the plate boundary fault (Shelly et al. 2007a; Ide et al. 2007). Shelly et al. (2007b) applied a matched filter technique (MFT) to 2-week-long continuous seismograms from western Shikoku Island and found rapid hypocentral migration of deep LFEs at speeds of $25-150 \mathrm{~km} / \mathrm{h}$, especially in the along-dip direction, much faster than the along-strike migration rates 
of $\sim 10 \mathrm{~km} /$ days associated with episodic tremor and slip (ETS) events. Owing to the limited analysis window, the long-term behavior of LFEs has not been well constrained. The JMA routinely determines hypocenters of LFEs to monitor temporal changes in the locking state along the Nankai subduction zone, but many LFEs in the existing catalog are missing because of overlapping waveforms during intensive burst-like LFEs and low signal-tonoise ratios (SNRs) of individual LFEs.

To improve our understanding of the behavior of longterm LFE activity along the tremor belt in Nankai, we applied the MFT to 11 years of continuous seismic data recorded by a dense, highly sensitive network, using LFEs with relatively high SNR values as template events. We examined the spatio-temporal evolution of LFEs and focused on interesting activity during two ETS episodes. We also identified numerous episodes of slow and rapid migration of LFEs during slow slip events (SSEs) along the Nankai subduction zone, indicating that a slow slip transient comprises many episodes of intermittent fault slip (Shelly et al. 2007b; Frank et al. 2018). The present study reports, for the first time, that rapid migration of LFEs appears to follow a diffusion law on shorter length scales. These features suggest that a diffusional process controls slow slip on multiple temporal and length scales.

\section{Methods}

We applied the MFT (Shelly et al. 2007a; Kato et al. 2013) to continuous waveform data retrieved by the Japanese national high-sensitivity seismograph network, Hi-net (NIED 2019a), and F-net (NIED 2019b), using three-component velocity seismograms from 1 April 2004 through 31 August 2015 (Fig. 1). As template events, we selected 3500 LFEs in southwestern Japan (western Shikoku and Tokai regions) from the JMA catalog (Additional file 1), recorded between 1 April 2004 and 31 August 2015 (Fig. 1). These selected LFEs have high signal-to-noise ratios (SNR). We divided the LFE zone into nine overlapping subregions (the MFT was executed for a total of 4147 events, because 647 templates are placed in the overlapping subregions), as shown in Fig. 1, and used selected template LFEs and

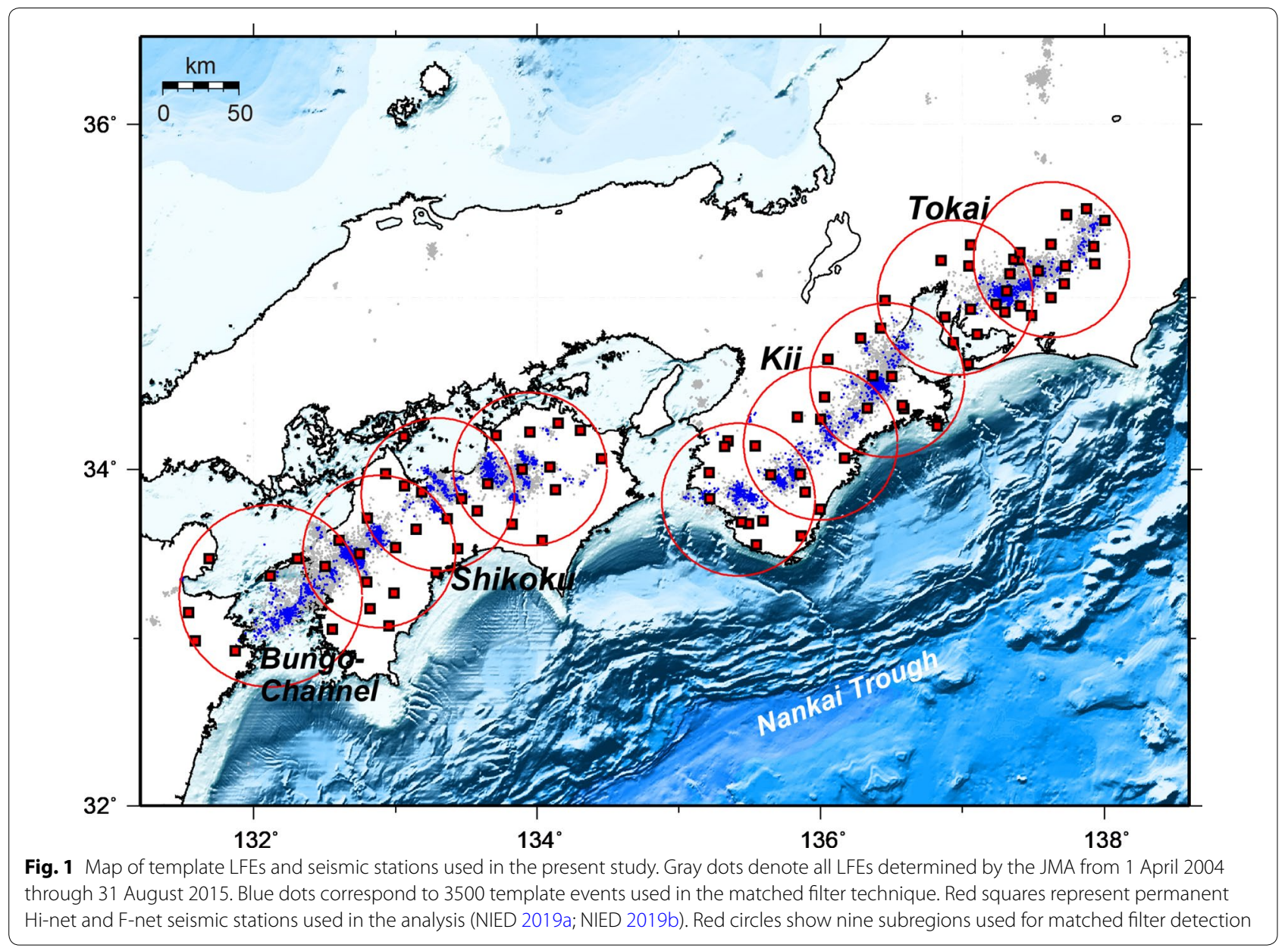


seismic stations within each subregion for detection; we required $\geq 27$ available channels on each local seismic network for a detected event to be retained. The continuous and template waveforms were preprocessed by applying a 2-6 Hz Butterworth bandpass filter and decimating the sampling rate from 100 to $20 \mathrm{~Hz}$. We then extracted a 6.0-s data window, starting $3.0 \mathrm{~s}$ prior to the arrival of the synthetic S-wave, with synthetic arrivals calculated using the one-dimensional velocity structure used by the JMA for routine earthquake locations. The event detection threshold was set at $9 \times M A D$, the median absolute deviation of the average correlation coefficient (ACC) calculated over each day. This level was chosen based on visual inspection of detected events, to suppress false detections while retaining as many true detections as possible. We assigned the location of the template event to each corresponding detection. We calculated the magnitude of the detected event based on the median value of the maximum amplitude ratios for all channels between the template and detected events, assuming that a tenfold increase in amplitude corresponds to a one-unit increase in magnitude (Peng and Zhao 2009).

To remove multiple detections, we used the template event location with the highest mean correlation coefficient in \pm 6.0 -s window from each detection. We also took away false detections corresponding to regular earthquakes in and around the studied region, based on the JMA hypocenter catalog. In addition, we removed false detections resulting from both temporal increases in the noise levels at local seismic stations and incident waveforms from distant moderate to large earthquakes [i.e., low cross-correlation coefficients with large amplitudes $(\mathrm{ACC} / \mathrm{MAD}<12$ and magnitude $\geq 1.1)$ ]. A total of 510,984 LFEs (Additional file 2) were detected along the Nankai subduction zone (Fig. 2), approximately $23 \times$ the number in the JMA catalog for the same period.

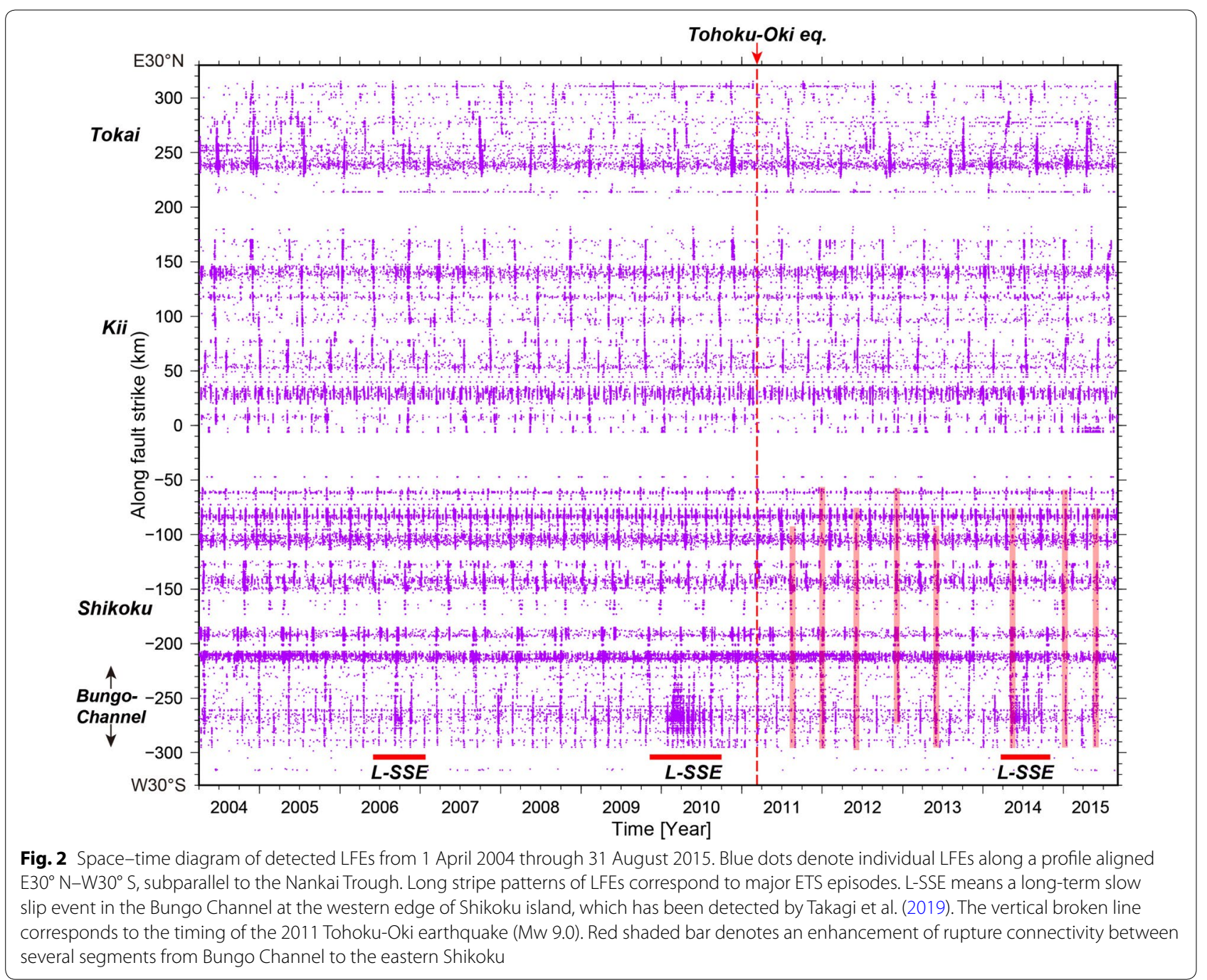




\section{Results and discussion}

Figure 2 shows space-time plots of detected LFEs from April 2004 to August 2015. Each major streak, occurring on a distance scale of up to $100 \mathrm{~km}$, indicates an intensive burst of LFEs migrating along the fault-strike direction, corresponding to a major ETS episode with equivalent $\mathrm{Mw} \sim 6.0$ (Hirose and Obara 2010; Sekine et al. 2010; Hirose and Kimura 2020). In the western part of Shikoku Island, we identify long-lasting bursts of LFEs during 2010 and 2014 (horizontal bars in Fig. 2); these correspond to geodetic detections of long-term slow slip events in the Bungo Channel using GNSS data (Yoshioka et al. 2015; Ozawa 2017). It is notable that series of LFE swarms occurred along strike intermittently during the long-term SSEs. These results are similar to bursts of LFEs detected during the 2006 SSE in the Mexican subduction zone (Frank et al. 2018). These observations suggest that a large-scale, longterm SSE contains a multitude of smaller, temporally clustered events (Jolivet and Frank 2020).

The equivalent moment magnitude of the 2010 SSE (Mw 6.9) in the Bungo Channel is larger than that of the 2014 event (Mw 6.5; Yoshioka et al. 2015; Ozawa 2017). The number of LFEs detected during the 2010 long-term SSE was also greater than the number detected during the 2014 event, indicating that the energy released by each SSE controls the extent of LFE activity. We also recognize a slight increase in the number of LFEs in 2006, which roughly corresponds to a minor long-term SSE $(\mathrm{Mw} \sim 6.3)$ reported by Takagi et al. (2019). This slight increase implies the occurrence of a smaller SSE than those in 2010 and 2014.

The $2011 \mathrm{Mw} 9.0$ Tohoku-Oki earthquake occurred during the analysis window. However, we observed no significant behavioral differences between LFEs before and after the megathrust rupture, except for an enhancement of rupture connectivity between several segments from Bungo Channel to the eastern Shikoku (red shaded bars in Fig. 2). The occurrence rate remained similar, regardless of stress perturbations induced by the megathrust rupture. This observation is consistent with Kono et al. (2020), who demonstrated that there were no temporal variations in the estimated rate of seismic moment release by tectonic tremor along the Nankai subduction zone as a result of the Tohoku-Oki earthquake. But, note that the spatiotemporal evolution of LFEs has changed from $\sim 2012$, in Shikoku island where major ETS episodes more frequently migrated long-distance through multiple segments than before the Tohoku-Oki earthquake. This behavioral difference has indicated an enhancement of rupture connectivity (Takagi et al. 2016), and resulted in an increase in the number of short-term SSEs with larger slip extent and seismic moment after 2012 (Hirose and Kimura 2020).

As a distinct example of an ETS episode (Fig. 3), major LFE activity was initiated beneath western Shikoku on 25 May 2012, then migrated eastward along strike, spreading over a distance of up to $100 \mathrm{~km}$ during the following 8 days. Five days later, a second burst of activity began further east, across an LFE gap. The secondary activity appears roughly in agreement with the extrapolated propagation of the front of the initial sequence. These migration fronts of LFEs showed clear parabolic curves (broken red lines in Fig. 3a); that is, the front location is proportional to the square root of time elapsed from the initial event $(\sim \sqrt{D t})$. The diffusion coefficient $D$ of the two sequences is $\sim 10^{4} \mathrm{~m}^{2} / \mathrm{s}$, within the range of values reported by previous studies using tectonic tremor signals (Ide 2010; Ando et al. 2012).

Before the main front of the migrating LFEs was reached, minor LFE activity started at a position of - $210 \mathrm{~km}$ projected along strike, indicated by the gray dotted-line rectangle in Fig. 3a. The occurrence rate of minor LFEs rapidly increased, to $\sim 8 \times$ the base rate $(8 \mathrm{R}$ in Fig. 3b), when the migrating front of the major LFEs merged with that of the minor ones. This observation suggests that a minor SSE combined with the major SSE propagating in the fault-strike direction. The merging of two SSEs probably caused local acceleration of fault slip, resulting in intensive LFE activity after the passage of the slip front. A temporal acceleration in slip induced by the merging of two SSEs has been reported along the Cascadia subduction zone based on geodetic measurements (Bletery and Nocquet 2020), but on a much larger scale.

As another example, Fig. 4a shows bilateral diffusion-like along-strike migration of the LFE front, with $D=10^{4} \mathrm{~m}^{2} / \mathrm{s}$, that initiated on 14 October 2009 in the eastern Kii Peninsula, Japan. Activation of LFEs started at a distance of $\sim 55 \mathrm{~km}$ along strike with a delay of approximately 5 days relative to passage of the main SSE front, which was moving toward the southwest. Delayed LFEs occurred to fill the LFE gap. As observed in Cascadia (Wech and Bartlow 2014), weak tremor-less slip might occur within this gap when the main front undergoes early migration toward the southwest, resulting in the connection of two spatially disjoint LFE areas. The LFEs terminate at a reduced slip rate when the migrating slip front reaches a non-critically stressed patch (Wech and Bartlow 2014), but the slight increase in loading rate can trigger additional slip at a distance.

During the slow long-distance migrations of LFEs, the migration patterns are categorized as diffusion-like and linear-like styles. The diffusive migrations can be identified during the other periods as listed up in Additional file 3: Table S1, in addition to the two periods in Figs. 3 

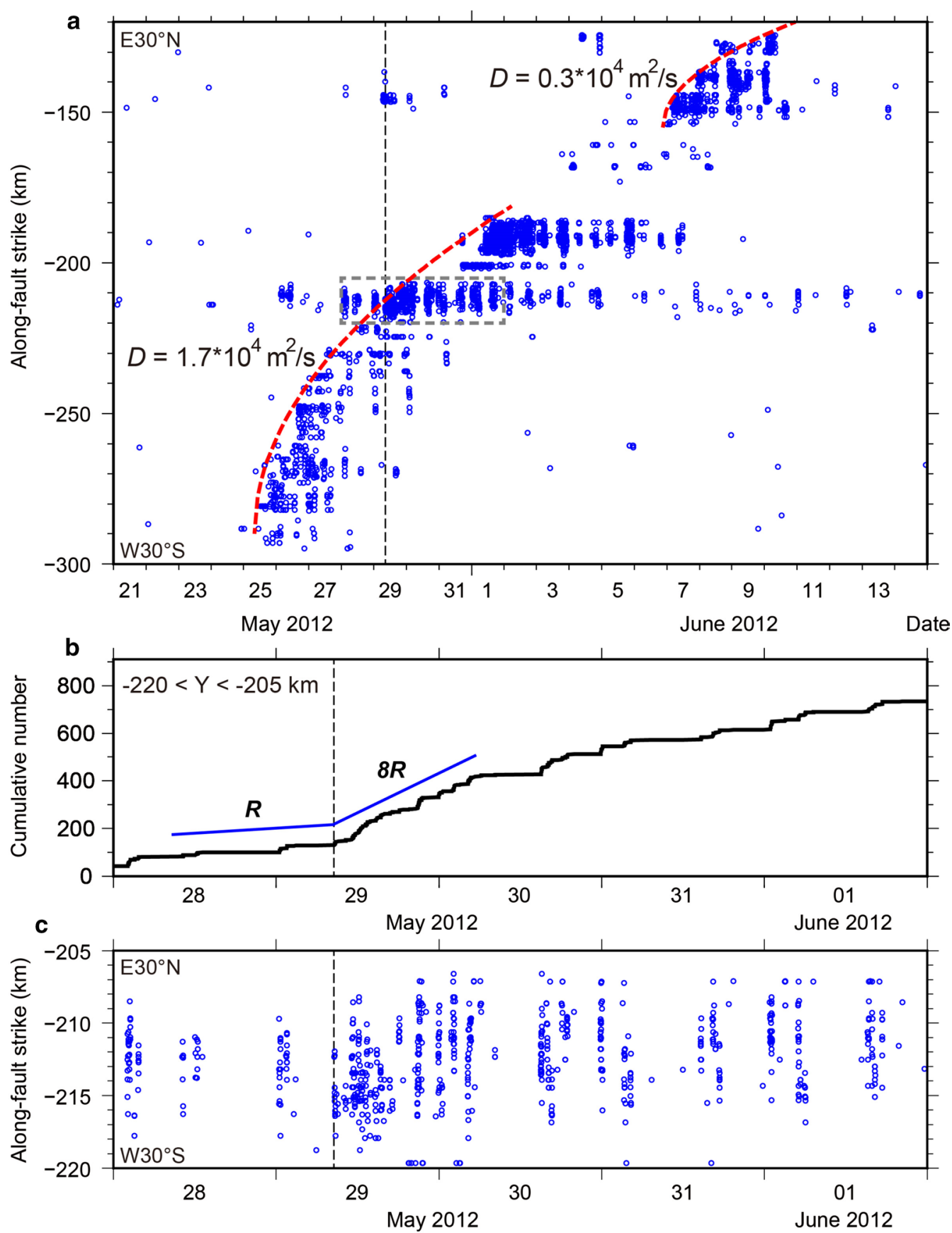

Fig. 3 An example of slow long-distance migration of LFEs during an ETS episode. a Space-time diagram of detected LFEs as a function of distance along fault strike (blue circles). Dashed red curves show diffusional fronts assuming the diffusion coefficients shown in the figure. The gray dotted-line rectangle represents the box of $\mathbf{b}$. $\mathbf{b}$ Time series of the cumulative number of LFEs within the gray dotted-line box in $\mathbf{a}$ $(-220<Y<-205)$. The vertical dashed line coincides with the timing at which the migrating front of LFEs passes. "R" indicates the LFE occurrence rate before the migration front passes. $\mathbf{c}$ A zoomed-in view of the gray dotted-line box in a

and 4. The diffusive migrations are often observed in the western Shikoku and the eastern Kii Peninsula. This may be due to a higher spatial resolution of LFEs at the two areas, where the radiated energies of tremors show the largest values among the entire tremor belt (Annoura et al. 2016), resulting in a high signal-to-noise ratio.

As shown in Figs. 3c and 4b, LFE activity occurred intermittently during or after the passage of the main 


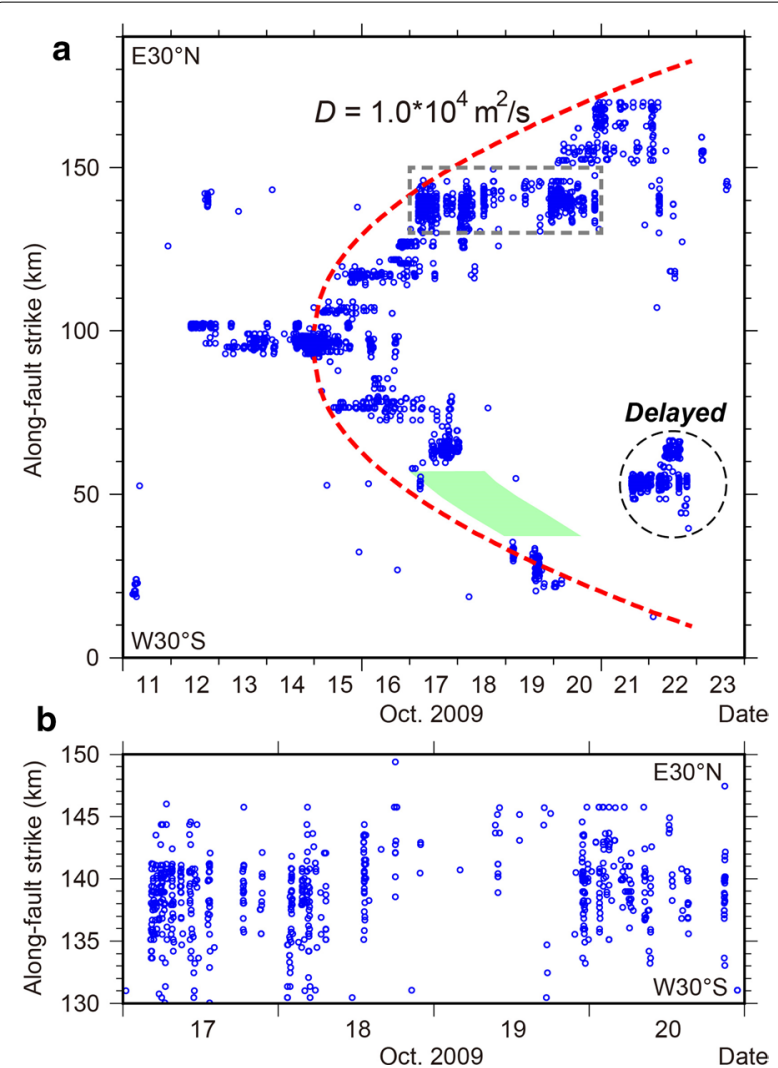

Fig. 4 An example of slow bilateral migration of LFEs during an ETS episode. a Space-time diagram of detected LFEs as a function of distance along fault strike. The green shaded area denotes a gap in LFEs along the migrating front. The gray dotted-line rectangle represents the boxed area enlarged in $\mathbf{b}$. Other symbols and meanings are the same as in Fig. 3. b A zoomed-in view of the boxed area in $\mathbf{a}$

front of migrating LFEs, indicated by striped patterns of intense activity that occurred as the front passed. Along the stripes, LFEs migrated in the along-dip and alongstrike directions. Intermittent LFEs were reported by Shelly et al. (2007b) for a few ETS episodes in western Shikoku. The present study discovers that intermittent LFEs are pervasive along the Nankai subduction zone and have occurred over at least the 11-year study window (Fig. 1). ETS also contains a series of smaller, temporally clustered slow slip transients, as seen during the long-term SSE at Bungo Channel (Fig. 2). These observations, on different temporal and spatial scales, imply that intermittent slow slip may be a scale-invariant property of slow earthquakes.

The intermittent stripes of activity show distinct spatial and temporal patterns in LFE swarm evolution over distances up to $15 \mathrm{~km}$ (Fig. 5). The migration speeds are quite fast, and reach $\sim 60 \mathrm{~km} / \mathrm{h}$; similarly, the rapid LFE migrations of Shelly et al. (2007b) occurred at rates of
$25-150 \mathrm{~km} / \mathrm{h}$ in western Shikoku. Some of fast migrations in the western Shikoku obey a diffusion-like evolution (broken red lines in Fig. 5), while others can be explained by linear propagations. It is hard to convincingly demonstrate the diffusion-like migration at small scale, because the spatial scale is approaching the spatial resolution of LFE location and the number of events during each fast sequence becomes small. However, we believe that fast short-distance migration also follows a diffusional behavior as like the slow long-distance migration of ETS episodes (Figs. 3 and 4).

In the case of the diffusive migration, $D$ is estimated to be $\sim 10^{5} \mathrm{~m}^{2} / \mathrm{s}$, an order of magnitude greater than for slow long-distance migration of ETS episodes (Figs. 3 and 4). Rapid migration can have a short duration ( $10 \mathrm{~min})$ and small length scale $(\sim 15 \mathrm{~km})$, in contrast to slow long-distance migration of ETS episodes (Figs. 3a and 4a). Along the Cascadia subduction zone, similar rapid migration of tremor streaks was reported by Ghosh et al. (2010). Most of the streaks propagated at velocities of $30-110 \mathrm{~km} / \mathrm{h}$, with a peak of $\sim 70 \mathrm{~km} / \mathrm{h}$, over distances of $<40 \mathrm{~km}$. Although Cascadia tremor migration speeds have the same velocity range as those in Nankai, the length scale in Cascadia is much greater than in Shikoku, which roughly corresponds to the width of the deep tremor band (Ide 2012).

In summary, slow long-distance migration of LFEs during an ETS episode contains a series of slip events comprising pulses of more rapid slip with short-distance migrations (Shelly et al. 2007b). The migration speed of LFEs increases with decreasing length scale, which is similar to observations of tectonic tremor migration (Houston et al. 2011; Obara et al. 2012). The present study suggests that high-speed migration of LFEs may follow a diffusion pattern, even at shorter length scales (Fig. 5). Two fast short-distance migrations in Fig. 5f, g occurred during the slow long-distance migration of ETS episodes shown in Fig. 3. These features imply that a diffusional process controls slow slip at multiple temporal and length scales. As Kano et al. (2018a) proposed, slow slip can be explained by a stress diffusion model with lubrication by fluid, consisting of along-strike heterogeneities in the effective strengths of brittle patches embedded in a ductile shear zone along the plate boundary fault.

We consider that the present LFE catalog (Additional file 2) will be useful for understanding the long-term behavior of minor and major slow slip events along the Nankai subduction zone. The present study uses only LFEs with relatively high SNR as template events to reduce the total computation time. The selected LFEs are representative of the overall behavior of slow slip transients, but increasing the number of template events in 


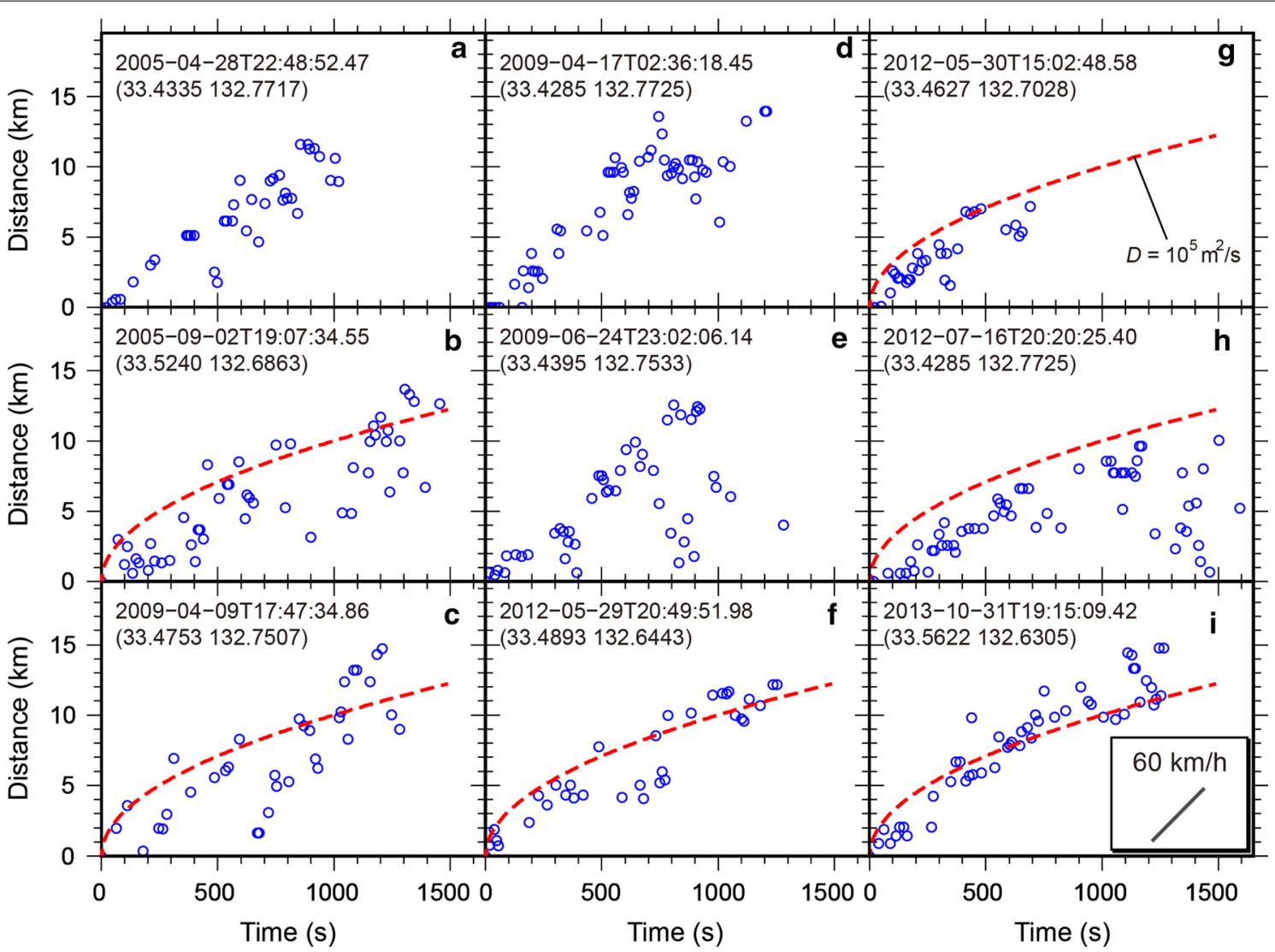

Fig. 5 Examples of rapid short-distance migration of LFEs in the western Shikoku. The vertical axis denotes distance from the initial event of each LFE burst. The dashed red curve in each panel shows a diffusional front assuming a coefficient of $10^{5} \mathrm{~m}^{2} / \mathrm{s}$. Time $t=0 \mathrm{~s}$ corresponds to the text label on each plot. The latitude and longitude of the initial event are shown in parentheses

future work will allow us to examine the spatio-temporal evolution of LFE activity at finer scales.

\section{Conclusions}

To examine long-term LFE activity along the deep tremor belt in the Nankai subduction zone, we applied the MFT to 11 years of continuous seismic data recorded by a dense and highly sensitive seismic network, using LFEs with high signal-to-noise ratios as template events. We detected a total of 510,984 LFEs, $\sim 23 \times$ the number in the JMA catalog for the same period. During long-term SSEs in the Bungo Channel, a series of intermittent, migrating LFE bursts occurred along the fault-strike direction, with slow hypocentral propagation speeds. Elastic energy released by longterm SSEs appears to control the extent of LFE activity. Over distances of up to $100 \mathrm{~km}$, we clearly identified slow, long-distance migrating fronts of LFEs during major ETS episodes, which evolve as a diffusion process along the fault-strike direction with a coefficient of $\sim 10^{4} \mathrm{~m}^{2} / \mathrm{s}$. This slow, diffusion-like migration closely matches the spatial and temporal evolution of tremor reported by previous studies. At shorter distance scales, to $\sim 15 \mathrm{~km}$, we discovered rapid diffusion-like migration of LFEs with a coefficient of $\sim 10^{5} \mathrm{~m}^{2} / \mathrm{s}$. Rapid migration of LFEs occurred intermittently in streaks during a major ETS episode. These observations indicate that a slow slip transient contains a multitude of smaller, temporally clustered fault slip events, which evolve as if governed by a diffusional process.

\section{Supplementary information}

Supplementary information accompanies this paper at https://doi. org/10.1186/s40623-020-01257-4.

Additional file 1. Table of catalog of the template LFEs. Date (Year, Month Day, Hour, Minute, Second), Latitude, Longitude, Depth and Magnitude.

Additional file 2. Table of catalog of the detected LFEs. Date (Year, Month, Day, Hour, Minute, Second), Latitude, Longitude, Depth and Magnitude.

Additional file 3: Table S1. List of major LFE activities showing diffusional migration along fault-strike. 


\section{Abbreviations}

LFE: Low-frequency earthquake; SSE: Slow slip event; JMA: Japan Meteorological Agency; NIED: National Research Institute for Earth Science and Disaster Resilience; ETS: Episodic tremor and slip; SNR: Signal-to-noise ratio.

\section{Acknowledgements}

We thank the National Research Institute for Earth Science and Disaster Resilience (NIED) and the Japan Meteorological Agency (JMA) for allowing us to use waveform data and earthquake catalogs. The manuscript benefitted from constructive comments by 2 anonymous referees and Editor David Shelly.

\section{Authors' contributions}

AK carried out the data analysis and the interpretation of the results and wrote the paper. SN helped with data preparation, numerical computation, and editing the manuscript. All authors read and approved the final manuscript.

\section{Funding}

This work was supported by JSPS KAKENHI Grant Number 26400447 , JP16H06473, JST CREST Grant Number JPMJCR1763 and the Ministry of Education, Culture, Sports, Science and Technology of Japan, under its Earthquake and Volcano Hazards Observation and Research Program.

\section{Availability of data and materials}

Data used in this study are available from the Data Management Center of NIED (https://hinetwww11.bosai.go.jp/auth/?LANG=en) and JMA (http:// www.data.jma.go.jp/svd/eqev/data/bulletin/index_e.html, http://www.data. jma.go.jp/svd/eqev/data/daily_map/index.html). The LFE catalog constructed in the present study can be downloaded from the Slow Earthquake Database website (Kano et al. 2018b; http://www-solid.eps.s.u-tokyo.ac.jp/ sloweq/).

\section{Ethics approval and consent to participate}

Not applicable.

\section{Consent for publication}

Not applicable.

\section{Competing interests}

The authors declare that they have no competing interests.

Received: 20 June 2020 Accepted: 25 August 2020

Published online: 09 September 2020

\section{References}

Ando R, Takeda N, Yamashita T (2012) Propagation dynamics of seismic and aseismic slip governed by fault heterogeneity and Newtonian rheology. J Geophys Res B Solid Earth 117:B11308. https://doi.org/10.1029/2012J B009532

Annoura S, Obara K, Maeda T (2016) Total energy of deep low-frequency tremor in the Nankai subduction zone, southwest Japan. Geophys Res Lett 43:2562-2567. https://doi.org/10.1002/2016GL067780

Araki E, Saffer DM, Kopf AJ et al (2017) Recurring and triggered slow-slip events near the trench at the Nankai Trough subduction megathrust. Science 356:1157-1160. https://doi.org/10.1126/science.aan3120

Bartlow NM (2020) A long-term view of episodic tremor and slip in Cascadia. Geophys Res Lett 47:e2019GL085303. https://doi.org/10.1029/2019g 1085303

Bletery Q, Nocquet JM (2020) Slip bursts during coalescence of slow slip events in Cascadia. Nat Commun 11:2159. https://doi.org/10.1038/s4146 7-020-15494-4

Frank WB, Rousset B, Lasserre C, Campillo M (2018) Revealing the cluster of slow transients behind a large slow slip event. Sci Adv 4:eaat0661. https:// doi.org/10.1126/sciadv.aat0661

Ghosh A, Vidale JE, Sweet JR et al (2010) Rapid, continuous streaking of tremor in Cascadia. Geochemis Geophys Geosyst 11:Q12010. https://doi. org/10.1029/2010GC003305

Hirose H, Kimura T (2020) Slip distributions of short-term slow slip events in1Shikoku, southwest Japan from 2001 to 2019 based on2tilt change measurements. J Geophys Res Solid Earth in press
Hirose H, Obara K (2010) Recurrence behavior of short-term slow slip and correlated nonvolcanic tremor episodes in western Shikoku, southwest Japan. J Geophys Res Solid Earth 115:B00A21. https://doi. org/10.1029/2008jb006050

Houston H, Delbridge BG, Wech AG, Creager KC (2011) Rapid tremor reversals in Cascadia generated by a weakened plate interface. Nat Geosci 4:404-409. https://doi.org/10.1038/ngeo1157

Ide S (2010) Striations, duration, migration and tidal response in deep tremor. Nature 466:356-359. https://doi.org/10.1038/nature09251

Ide S (2012) Variety and spatial heterogeneity of tectonic tremor worldwide. J Geophys Res Solid Earth 117:B03302. https://doi.org/10.1029/2011 J B008840

Ide S, Shelly DR, Beroza GC (2007) Mechanism of deep low frequency earthquakes: further evidence that deep non-volcanic tremor is generated by shear slip on the plate interface. Geophys Res Lett 34:L03308. https://doi. org/10.1029/2006GL028890

Jolivet R, Frank WB (2020) The Transient and Intermittent Nature of Slow Slip. AGU Adv 1:e2019AV000126. https://doi.org/10.1029/2019av000126

Kano M, Kato A, Ando R, Obara K (2018a) Strength of tremor patches along deep transition zone of a megathrust. Sci Rep 8:3655. https://doi. org/10.1038/s41598-018-22048-8

Kano M, Aso N, Matsuzawa T, Ide S, Annoura S, Arai R et al (2018b) Development of a Slow Earthquake Database. Seismol Res Lett 89(4):1566-1575. https://doi.org/10.1785/0220180021

Kato A, Fukuda J, Obara K (2013) Response of seismicity to static and dynamic stress changes induced by the 2011 M9.0 Tohoku-Oki earthquake. Geophys Res Lett 40:3572-3578. https://doi.org/10.1002/grl.50699

Katsumata A, Kamaya N (2003) Low-frequency continuous tremor around the Moho discontinuity away from volcanoes in the southwest Japan. Geophys Res Lett 30(1):1020. https://doi.org/10.1029/2002GL015981

Kono Y, Nakamoto K, Hiramatsu Y (2020) Temporal variation in seismic moment release rate of slow slips inferred from deep low-frequency tremors in the Nankai subduction zone. Earth Planets Space 72:12. https ://doi.org/10.1186/s40623-020-1142-3

National Research Institute for Earth Science and Disaster Resilience (2019a) NIED Hi-net. https://doi.org/10.17598/nied.0003

National Research Institute for Earth Science and Disaster Resilience (2019b) NIED F-net. https://doi.org/10.17598/nied.0005

Obara K (2002) Nonvolcanic deep tremor associated with subduction in southwest Japan. Science 296:1679-1681. https://doi.org/10.1126/scien ce. 1070378

Obara K, Kato A (2016) Connecting slow earthquakes to huge earthquakes. Science (80-) 353:253-257. https://doi.org/10.1126/science.aaf1512

Obara K, Matsuzawa T, Tanaka S, Maeda T (2012) Depth-dependent mode of tremor migration beneath Kii Peninsula, Nankai subduction zone. Geophys Res Lett 39:L10308. https://doi.org/10.1029/2012GL051420

Ozawa S (2017) Long-term slow slip events along the Nankai trough subduction zone after the 2011 Tohoku earthquake in Japan. Earth Planets Space 69:56. https://doi.org/10.1186/s40623-017-0640-4

Peng Z, Gomberg J (2010) An integrated perspective of the continuum between earthquakes and slow-slip phenomena. Nat Geosci 3:599-607. https://doi.org/10.1038/ngeo940

Peng Z, Zhao P (2009) Migration of early aftershocks following the 2004 Parkfield earthquake. Nat Geosci 2:877-881. https://doi.org/10.1038/ngeo697

Sekine S, Hirose H, Obara K (2010) Along-strike variations in short-term slow slip events in the southwest Japan subduction zone. J Geophys Res Solid Earth 115:B00A27. https://doi.org/10.1029/2008jb006059

Shelly DR, Beroza GC, Ide S (2007a) Non-volcanic tremor and low-frequency earthquake swarms. Nature 446:305-307. https://doi.org/10.1038/natur e05666

Shelly DR, Beroza GC, Ide S (2007b) Complex evolution of transient slip derived from precise tremor locations in western Shikoku, Japan. Geochem Geophys Geosyst 8:Q10014. https://doi.org/10.1029/2007GC001640

Takagi R, Obara K, Maeda T (2016) Slow slip event within a gap between tremor and locked zones in the Nankai subduction zone. Geophys Res Lett 43:1066-1074. https://doi.org/10.1002/2015GL066987

Takagi R, Uchida N, Obara K (2019) Along-strike variation and migration of long-term slow slip events in the western Nankai subduction zone, Japan. J Geophys Res Solid Earth 124:3853-3880. https://doi. org/10.1029/2018JB016738 
Wallace LM (2020) Slow Slip Events in New Zealand. Annu Rev Earth Planet Sci 48:8.1-8.29. https://doi.org/10.1146/annurev-earth-071719-055104

Wech AG, Bartlow NM (2014) Slip rate and tremor genesis in Cascadia. Geophys Res Lett 41:392-398. https://doi.org/10.1002/2013GL058607

Yokota Y, Ishikawa T (2020) Shallow slow slip events along the Nankai Trough detected by GNSS-A. Sci Adv 6:eaay5786. https://doi.org/10.1126/sciad v.aay 5786

Yoshioka S, Matsuoka Y, Ide S (2015) Spatiotemporal slip distributions of three long-term slow slip events beneath the Bungo Channel, southwest
Japan, inferred from inversion analyses of GPS data. Geophys J Int 201:1437-1455. https://doi.org/10.1093/gji/ggv022

\section{Publisher's Note}

Springer Nature remains neutral with regard to jurisdictional claims in published maps and institutional affiliations.

\section{Submit your manuscript to a SpringerOpen ${ }^{\circ}$ journal and benefit from:}

- Convenient online submission

- Rigorous peer review

- Open access: articles freely available online

- High visibility within the field

- Retaining the copyright to your article

Submit your next manuscript at $\gg$ springeropen.com 